\title{
The effect of acid leaching time in modifying natural zeolite as catalyst for toluene steam reforming
}

\author{
Joko Waluyo ${ }^{1,2}$, I.G.B.N. Makertihartha ${ }^{1}$, Herri Susanto ${ }^{1, *}$ \\ ${ }^{l}$ Department of Chemical Engineering, Institut Teknologi Bandung, Jalan Ganesha 10 Bandung, Jawa \\ Barat, Indonesia \\ ${ }^{2}$ Department of Chemical Engineering, Universitas Sebelas Maret, Jalan Ir. Sutami 36A Surakarta, \\ Jawa Tengah, Indonesia
}

\begin{abstract}
Tar accumulation can result in blockage, corrosion, and poisoning of catalyst. One of the methods applicable for tar removal is by using a catalyst that enhances steam reforming reaction. In this study, natural zeolites were modified for the use as tar steam reforming catalyst. This study also covers characterizing the modified natural zeolite by ion exchange and acid leaching, and measuring its activity as toluene steam reforming catalyst. The XRD pattern showed that natural zeolite contains three crystalline phases, i.e. mordenite, clinoptilolite, and heulandite. The main structure of the mordenite phase was also detected by using FTIR analysis on T-O stretching band with the range of $1045-1075 \mathrm{~cm}^{-1}$. The zeolite modification by ion exchange and acid leaching resulted in decreasing content of impurities, such as $\mathrm{Na}$ and $\mathrm{K}$, and the decrease in crystallinity from $68.8 \%$ to $61.8 \%$. The surface area increased from 16 $\mathrm{m}^{2} / \mathrm{g}$ to $31.4 \mathrm{~m}^{2} / \mathrm{g}$ and $161.8 \mathrm{~m}^{2} / \mathrm{g}$ for ZMH (after ion exchange), ZM3 (after acid leaching for 3 hour), and ZM6 (after acid leaching for 6 hour) respectively. Theses catalyst gave toluene conversion of $30.5 \%$ to $42.6 \%$ and $54 \%$ respectively.
\end{abstract}

\section{Introduction}

Gasification is a thermal conversion process that can converts wastes or biomass into syngas. The syngas obtained can be utilized for electricity production, synthesis of valuable chemicals such as methanol, DME, $\mathrm{H}_{2}$, other Fischer-Tropsch fuel, etc. However, syngas still contains impurities such as particulates, ammonia, $\mathrm{H}_{2} \mathrm{~S}$ and $\operatorname{tar}$ [1] that must be removed prior to its utilization.

Tar can be defined as complex compounds of polyaromatic hydrocarbons with higher molecular weight as compared to benzene. The tar content in syngas ranges from 10 $150,000 \mathrm{mg} / \mathrm{Nm}^{3}$ depending on the type and operating condition of the gasifier [2]. Tar accumulation may cause blockage, corrosion in pipeline, and also deactivation of catalyst

*Corresponding author: herri@,che.itb.ac.id 
for chemical synthesis. The presence of tar leads to both operational and maintenance problems in gasification processes.

The advantages in using a catalytic process for tar removal includes the avoidance of producing hard to handle liquid waste, high thermal efficiency as it can be carried out at the temperature in the range that the gasifier operates, and the increase in $\mathrm{H}_{2}$ and $\mathrm{CO}$ concentration [3]. Steam reforming reactions for tar removal have additional advantages such as increasing the $\mathrm{H}_{2}$ content in syngas and reduce the amount of carbon deposits on the catalyst, which extends the catalyst lifetime [4]. Nickel is widely used as a catalyst for tar steam reforming with various supports. Natural zeolites are relatively inexpensive and so the use of natural zeolite catalyst is economically feasible if the produced syngas is to be utilized for small-scale power generation. The natural zeolite has been widely developed for industrial use in various applications, such as cracking, hydrocracking and isomerization[5]. Natural zeolite has diverse crystal phase, mordenite, clinoptilolite and mesolite are commonly used as a catalyst.

Mordenite can be used as a steam reforming catalyst [6, 7]. Mordenite can be obtained naturally or through synthesis. Natural zeolite has several disadvantages for use as a catalyst such as containing impurities and having low surface area. The existing impurities such as $\mathrm{Na}, \mathrm{K}$ have a low melting point and when the modified zeolite is used as a catalyst at high temperature, it may decrease the activity of the catalyst. It is, therefore, necessary to modify or improve these properties.

Zeolite modification can be performed by conducting ion exchange, acid leaching, alkaline leaching or hydrothermal treatment. In this study, the natural zeolite is modified by ion exchange and acid leaching. Acid leaching are performed with the intention of removing impurities and also possibly increasing the surface area through dealumination. The dealumination process causes increased thermal resistance and decreases the acidity of the zeolite. The purpose of this study is to determine the effect of acid leaching duration, the characteristics of zeolite and its activity.

\section{Material and method}

\subsection{Material}

Natural zeolite collected from Wonosari, Yogyakarta was used as raw material. The zeolite used has a size of 5-10 mesh. Solution of $\mathrm{NH}_{4} \mathrm{NO}_{3}$ and $\mathrm{HNO}_{3}$ were used as ion exchange and acid leaching agent to remove impurities and improve catalyst characteristics. $\mathrm{NH}_{4} \mathrm{NO}_{3}$, $\mathrm{HNO}_{3}$, and toluene were purchased from Merk. Natural zeolite pulverized into a powder then characterized using XRD to determine the crystal phase. XRF and EDX are used for characterizing elemental composition.

\subsection{Modification of zeolite}

Natural zeolite was washed using demineralized water, followed by drying. The first modification was an ion exchange to make H-zeolite. One gram of zeolite stirred and refluxed with $10 \mathrm{~mL} 2 \mathrm{M} \mathrm{NH} \mathrm{NO}_{3}$ at $90^{\circ} \mathrm{C}$ for 2 hours. Ion exchange produces $\mathrm{NH}_{4}$-zeolite and then washed with distillates water followed by calcination at $550^{\circ} \mathrm{C}$ for 12 hours to remove $\mathrm{NH}_{3}$ and obtain $\mathrm{H}$-zeolite. Acid leaching was carried out by reflux using $6 \mathrm{M} \mathrm{HNO}_{3}$ at $90^{\circ} \mathrm{C}$ with the variation of 3 hours (ZM-3) and 6 hours (ZM-6) leaching time and $20 \mathrm{wt}$. / wt. At the end of a modification of sample washed with demine water and calcined at $550^{\circ} \mathrm{C}$ for 12 hours. Table 1 shows the condition for modification process. 
Table 1. Modification condition of natural zeolite

\begin{tabular}{|c|c|c|c|}
\hline No & Zeolite & ion exchange & acid leaching \\
\hline 1 & $Z M H$ & $\mathrm{NH}_{4} \mathrm{NO}_{3} 2 \mathrm{M}, 2$ hour & - \\
\hline 2 & $\mathrm{ZM} 3$ & $\mathrm{NH}_{4} \mathrm{NO}_{3} 2 \mathrm{M}, 2$ hour & $\mathrm{HNO}_{3} 6 \mathrm{M}, 3$ hour \\
\hline 3 & $\mathrm{ZM} 6$ & $\mathrm{NH}_{4} \mathrm{NO}_{3} 2 \mathrm{M}, 2$ hour & $\mathrm{HNO}_{3} 6 \mathrm{M}, 6$ hour \\
\hline
\end{tabular}

\subsection{Characterization of catalyst}

The sample pulverized into powder with particle size of less than 100 microns. The crystalline morphology structure was characterized using X-Ray Diffraction with Bruker D8 Advance type. The diffractometer uses $\mathrm{CuK} \alpha$ radiation by recording $2 \theta$ at room temperature of $5^{\circ}-50^{\circ}$, scan rate $76.8^{\circ} /$ minute and step size 0.019 . For surface and pore structure, liquid nitrogen absorption was measured at $77.35 \mathrm{~K}$ using Nova 3200e. The Brunauer-Emmet-Teller (BET) method used to measure surface area, pore volume and pore size using the Barrett-Joyner-Halenda (BJH) method. The Composition of the zeolite element was characterized by field-emission electron microscope (FE-SEM) and energy disperse X-ray (EDX) and also XRF. Infrared absorption was performed using FTIR spectrophotometer with a wavelength in the range $400-4500 \mathrm{~cm}^{-1}$.

\subsection{Activity test of zeolite}

Two grams of zeolite incorporated into tar cracking fixed bed reactor with a diameter of 2 $\mathrm{cm}$ and a length of $50 \mathrm{~cm}$. The reactor conditions were set at 1 atm and cracking temperature $750^{\circ} \mathrm{C}$. Nitrogen as a carrier gas is passed through the tar model (toluene) at ambient condition and regulated by using a needle valve and measured using a flow meter. Water flowed using a syringe pump. The flow rate was adjusted to tar flowed having a concentration of $50 \mathrm{~g} / \mathrm{Nm}^{3}$ and has a ratio of steam/ tar 10 . The tar rate used was 0.21 grams/hour and the rate for $\mathrm{N}_{2} 8400 \mathrm{~mL} / \mathrm{hr}$. Tar cracking was done for 8 hours. The toluene concentration in and out of the reactor was analyzed using GC-FID Shimadzu GC-14B. Spent cracking catalysts were tested using TGA to determine the possibility of carbon deposits.

\section{Result and discussion}

\subsection{Characteristic of zeolite}

The XRD results show that natural zeolite of Wonosari containing Mordenite, Clinoptilolite and Heulandite crystal phase. Unique diffraction for mordenite at $2 \theta 6.5^{\circ} ; 9.76^{\circ} ; 13.43^{\circ}$; $19.59^{\circ} ; 22.18^{\circ} ; 25.6^{\circ} ; 26.22^{\circ} ; 27.65^{\circ} ; 28.25^{\circ}$, while $2 \theta$ at $25.7^{\circ} ; 26.02^{\circ} ; 28.57^{\circ}$ and $30.02^{\circ}$ are unique diffraction for clinoptilolite and heulandite. Ion exchange results in their missing of diffraction peaks of zeolite (Figure 1). This indicates the loss of some zeolite impurities especially $\mathrm{Na}$ and $\mathrm{K}$ which have been replaced with $\mathrm{H}^{+}$cations, such as the results of elemental composition analysis presented in Table 2. In modification with acid leaching, there is a slight decrease from the relative height of the peak on the diffraction. This is due to the destruction of heulandite structures. Kim, Hwang [8], states that the heulandite is easily destroyed by acid leaching while mordenite and clinoptilolite are stronger against acid leaching. The decrease in intensity indicates a decrease in the number of $\mathrm{Al}$ atoms, resulting in a decrease in the crystallinity of the zeolite (Table 2). 


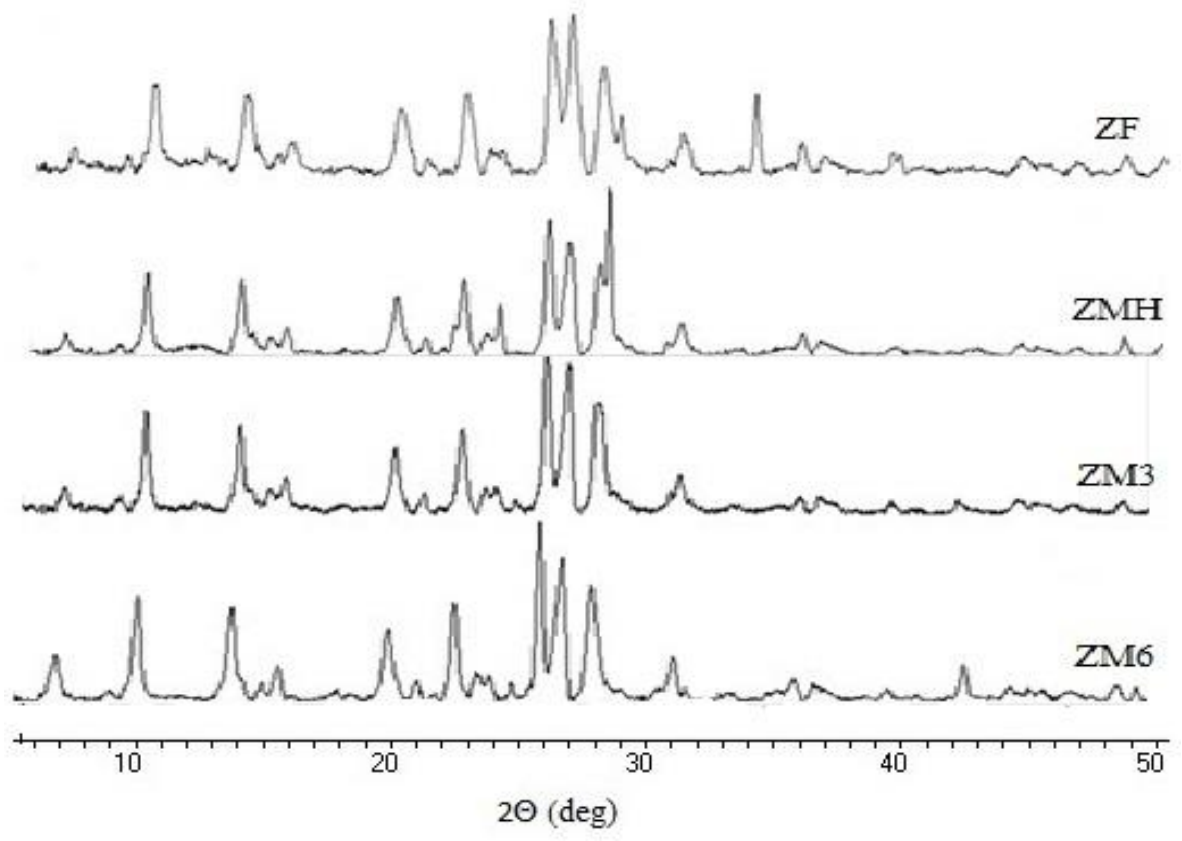

Fig. 1. XRD pattern of parent zeolite and after modification

Table 2. Elemental composition as determine by EDX analysis

\begin{tabular}{|c|c|c|c|c|c|}
\hline No & Samples & $\mathrm{ZF}$ & $\mathrm{ZH}$ & ZM3 & ZM6 \\
\hline 1 & \multicolumn{5}{|c|}{ Elemental composition (EDX analysis) } \\
\hline & $\mathrm{Si}$ & 29.75 & 32.47 & 31.48 & 31.68 \\
\hline & $\mathrm{Al}$ & 7.09 & 7.85 & 7.23 & 6.71 \\
\hline & $\mathrm{Na}$ & 0.72 & 0.42 & 0.22 & 0.22 \\
\hline & $\mathrm{K}$ & 0.65 & 0.17 & 0 & 0 \\
\hline & $\mathrm{Mg}$ & 0.87 & 0.53 & 0.53 & 0.58 \\
\hline & $\mathrm{Ca}$ & 3.06 & 2.15 & 1.72 & 1.75 \\
\hline & $\mathrm{Fe}$ & 2.57 & 2.21 & 1.66 & 2.01 \\
\hline & Ti & 0.27 & 0.34 & 0.27 & 0.34 \\
\hline & $\mathrm{O}$ & 55.02 & 51.31 & 51.21 & 51.19 \\
\hline & $\mathrm{C}$ & 0 & 2.55 & 5.68 & 5.52 \\
\hline 2 & \multicolumn{5}{|c|}{ Psychochemical properties } \\
\hline & $\mathrm{Si} / \mathrm{Al}$ ratio* & - & 5.09 & 5.02 & 5.61 \\
\hline & АвЕт $\left(\mathrm{m}^{2} / \mathrm{g}\right)$ & - & 16 & 31.4 & 161.8 \\
\hline & $V_{t}\left(\mathrm{~cm}^{3} / \mathrm{g}\right)$ & - & 0.094 & 0.086 & 0.159 \\
\hline & Crystallinity & - & $66.3 \%$ & $63.7 \%$ & $61.8 \%$ \\
\hline
\end{tabular}

*Analyzed by XRF

The zeolite structure for the mordenite phase can also be detected by using FTIR analysis (Figure 2) on a T-O stretching band with a range of $1045-1075 \mathrm{~cm}^{-1}$. In that range, the higher the wavenumber indicates that there is a dealumination or decreasing number of $\mathrm{Al}$ atoms in the tetrahedral framework [9]. FTIR spectra also shows the presence of amorphous or quartz $\mathrm{SiO}_{2}$ silicate on a waveband of about $795 \mathrm{~cm}^{-1}$. While at wavenumber about $450 \mathrm{~cm}^{-1}$ is another $\mathrm{Si}-\mathrm{O}-\mathrm{Si}$ bonding. 
Vibration at the wavelength of $1600-3700 \mathrm{~cm}^{-1}$ is the wavelength for zeolitic water that indicates an interaction between hydroxyl and cation. FTIR analysis results in ZF and $\mathrm{ZMH}$ show the appearance of a wavelength at $2854 \mathrm{~cm}^{-1}$ and $2928 \mathrm{~cm}^{-1}$. After acid leaching (ZM3 and ZM6) the wavelength disappears indicating that the hydroxyl bond has been removed. In the dealumination process, the loss of $\mathrm{Al}$ from the tetrahedral framework can be an extra framework octahedral $\mathrm{Al}$, this is apparent at the wavelengths formed in the $3700-3650 \mathrm{~cm}^{-1}$ wavelength range.

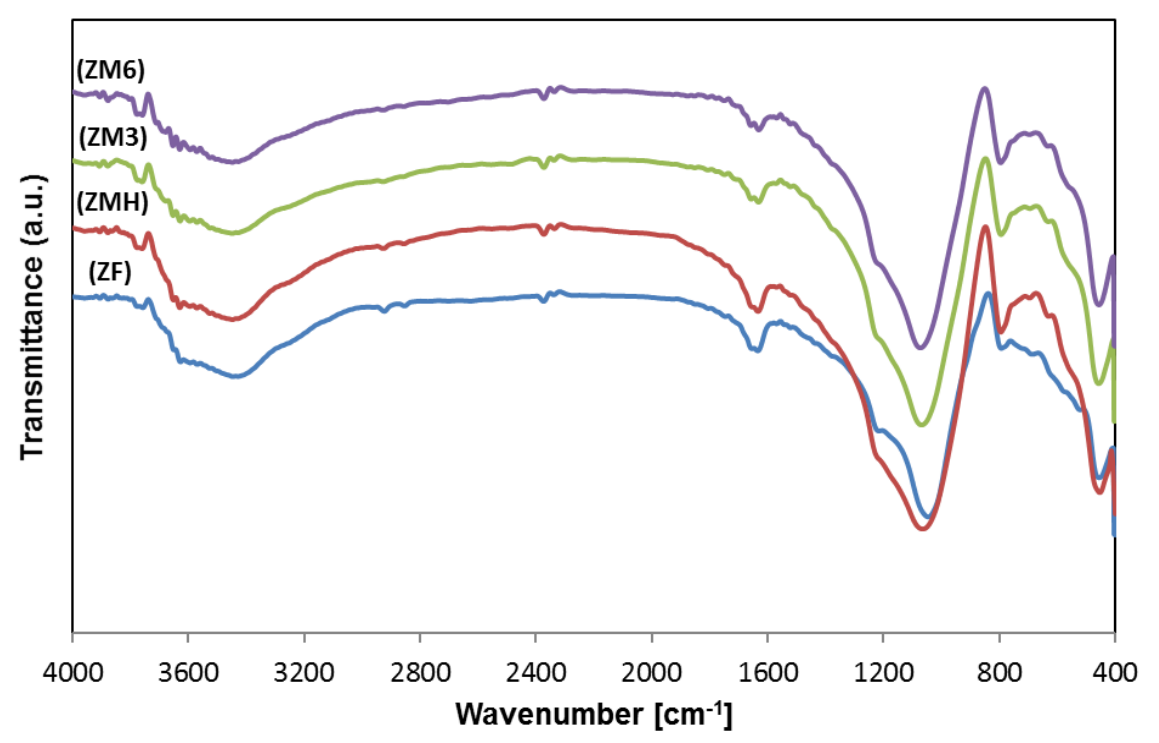

Fig. 2. FTIR spectrum of parent zeolite and modified zeolite

Acid leaching in natural zeolite can remove impurities and some aluminum atoms from the zeolite framework and lead to changes in pore structure such as an increase in pore volume at $38 \AA$ pore diameter. In acid leaching with $\mathrm{HNO}_{3}$, the XRF results show that the $\mathrm{Si} / \mathrm{Al}$ ratio does not increase significantly, this is due to the formation of extra framework aluminum (EFAL) as described in FTIR characterization above. The low $\mathrm{Si} / \mathrm{Al}$ ratio makes the acidity of zeolite is also relatively not too high. This will be advantageous for reactions related to cracking or breaking of bonds.

\subsection{Catalytic activity test}

Modifying the natural zeolite with mordenite as the main phase, through ion exchange and acid leaching can increase the conversion of toluene cracking by reaction of steam reforming. Conversion of toluene with the modified natural zeolite can reach up to $54 \%$ (Figure 3), this is due to modification by acid leaching can increase the surface area of zeolite mordenite, and the toluene will easily react with steam. Acid leaching time affects the surface area of the zeolite, the longer the leaching makes the surface area become larger as presented in Table 2. 


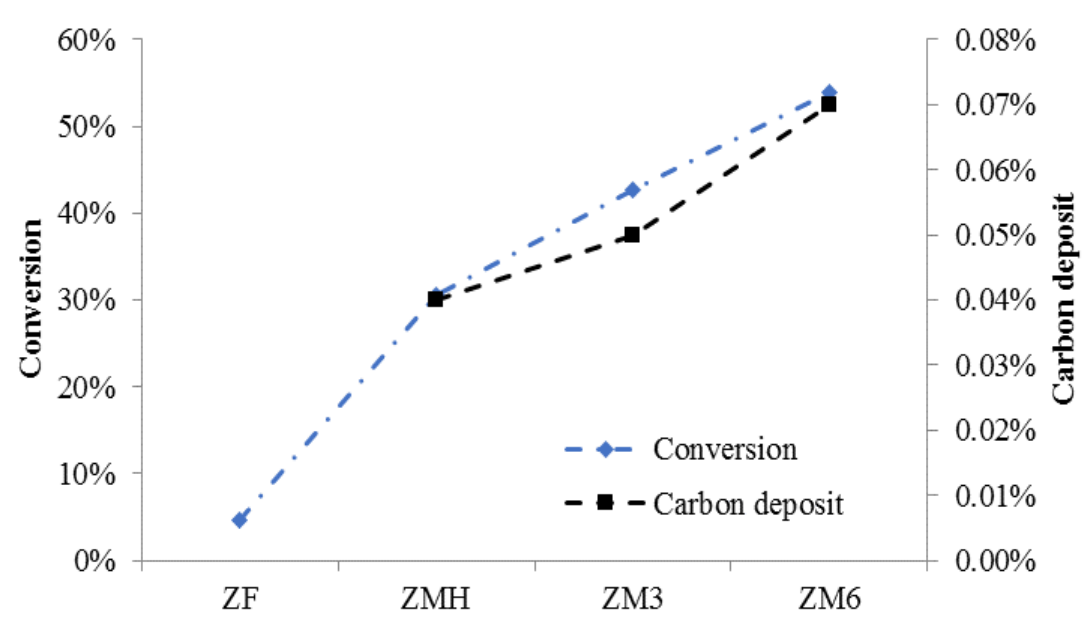

Fig. 3. Conversion of toluene and carbon deposits on various zeolites modification

\section{Conclusions}

The mordenite crystal phase of the natural zeolite is unchanged after modification by acid leaching using the $\mathrm{HNO}_{3}$ solution, but the heulandite crystal phase undergoes a reduction. The longer the acid leaching can increase the surface area of the natural zeolite because the loose aluminum from the zeolite framework forms EFAL so that the catalyst activity increases.

This topic is a part of the doctoral research in Chemical Engineering Dept. ITB. The authors would like to acknowledge the financial support from Hibah P3MI, Institut Teknologi Bandung 2017. Thanks to Dr Jenny Rizkiana for valuable discussion.

\section{References}

1. N. Abdoulmoumine, S. Adhikari, A. Kulkarni, and S. Chattanathan, Applied Energy, 155, 294-307 (2015)

2. M. Asadullah, Renewable and Sustainable Energy Reviews, 40, 118-132 (2014)

3. S. Schmidt, S. Giesa, A. Drochner, and H. Vogel, Catalysis Today, 175(1), 442-449 (2011)

4. M. Kaewpanha, G. Guan, X. Hao, Z. Wang, Y. Kasai, S. Kakuta, K. Kusakabe, and A. Abudula, Journal of the Taiwan Institute of Chemical Engineers, 44(6), 1022-1026 (2013)

5. J. Waluyo, T. Richards, I. Makertihartha, and H. Susanto, Asean Journal of Chemical Engineering, 17(1), 37-45 (2017)

6. J.F. Da Costa-Serra, M.T. Navarro, F. Rey, and A. Chica, International Journal of Hydrogen Energy, 37(8), 7101-7108 (2012)

7. T. Matsumoto, T. Nishiguchi, H. Kanai, K. Utani, Y. Matsumura, and S. Imamura, Applied Catalysis A: General, 276(1-2), 267-273 (2004)

8. M.H. Kim, U.-C. Hwang, I.-S. Nam, and Y. Gul Kim, Catalysis Today, 44(1-4), 57-65 (1998)

9. K. Elaiopoulos, T. Perraki, and E. Grigoropoulou, Microporous and Mesoporous Materials, 134(1-3), 29-43 (2010) 